Keywords: tumour microenvironment; cancer metabolism; cancer cell metabolism; tumour metabolism; metabolism; metabolic profile

\title{
Tumour microenvironment factors shaping the cancer metabolism landscape
}

\author{
Dimitrios Anastasiou ${ }^{\star, 1}$ \\ ${ }^{1}$ Cancer Metabolism Laboratory, The Francis Crick Institute, 1 Midland Road, London NW1 1AT, UK
}

Cancer cells exhibit metabolic alterations that distinguish them from healthy tissues and make their metabolic processes susceptible to pharmacological targeting. Although typical cell-autonomous features of cancer metabolism have been emerging, it is increasingly appreciated that extrinsic factors also influence the metabolic properties of tumours. This review highlights evidence from the recent literature to discuss how conditions within the tumour microenvironment shape the metabolic character of tumours.

A primary goal in designing new cancer therapies is to target cancer cells specifically and, at the same time, spare healthy tissues. Cancer cells exhibit, among others, characteristic features in the way they utilise nutrients to survive and proliferate. Although in many cases the ensemble of small molecules and enzymatic activities underlying metabolic processes in cancer are, by and large, similar to the ones in healthy tissues, changes in the expression levels of metabolic enzymes, expression of alternative enzyme isoforms or mutations in genes encoding metabolic enzymes have all been implicated in altering the metabolism of tumours (Pavlova and Thompson, 2016). Oncogenic and tumour suppressor pathways that drive cancer development have been shown to promote these metabolic features, which are therefore stably propagated throughout tumour development. This has raised hopes that metabolic enzymes comprise good targets for cancer therapy (Galluzzi et al, 2013; Elia et al, 2016).

Metabolism encompasses the chemical processes that allow cells to use available nutrient resources and sustain their survival and propagation. As such, the environment in which tumours emerge is bound to have an influence in their metabolism: what nutrients and other factors that enable metabolism, such as oxygen, are available, at what quantities, whether other cells are present that compete for or provide such nutrients are all factors that can influence the metabolic behaviour of tumours.

This review focuses on recent advances in our understanding of cancer metabolism with emphasis on the influence of the tumour microenvironment. In particular, I will discuss work in mice and humans that points to a synergism between the tumour environment and genetics in determining the metabolic profiles of cancers, and will put this evidence in context of the prevailing views on how glucose and glutamine support cancer metabolism. I will then explore factors that are thought to operate within the tumour environment, in particular fluctuations in oxygen and nutrient availability, and will describe newly discovered mechanisms by which these factors impact metabolism. Finally, I will use select examples to outline how various tumour stromal cells, which are also subject to similar metabolic requirements as cancer cells, contribute to the metabolic conditions found within the tumour microenvironment.

\section{OVERVIEW OF CENTRAL METABOLISM-GLUCOSE AND GLUTAMINE}

Glucose is an abundant source of carbon in mammals, and organs such as the brain and the heart exhibit high levels of glucose uptake. Some tumours show increased glucose uptake relative to the surrounding normal tissues and this feature has been exploited for diagnostic imaging using ${ }^{18} \mathrm{~F}$-deoxyglucose (FDG), a radioactive glucose analogue that cannot be fully metabolised, for positron emission tomography (PET).

Glucose uptake can be promoted by gene expression or signalling changes that lead to increased glucose transporter expression, particularly GLUT1, at the plasma membrane. Once into cells, a major route for glucose catabolism is glycolysis (Figure 1). Pathways that branch out of glycolysis can utilise products of glucose catabolism for the synthesis of nucleotides, lipids or amino acids. Depending on cell type and environmental conditions, glucose-derived pyruvate enters into the mitochondrial TCA cycle as an intact 3-carbon unit via pyruvate carboxylase, or

*Correspondence: Dr D Anastasiou; E-mail: dimitrios.anastasiou@crick.ac.uk 


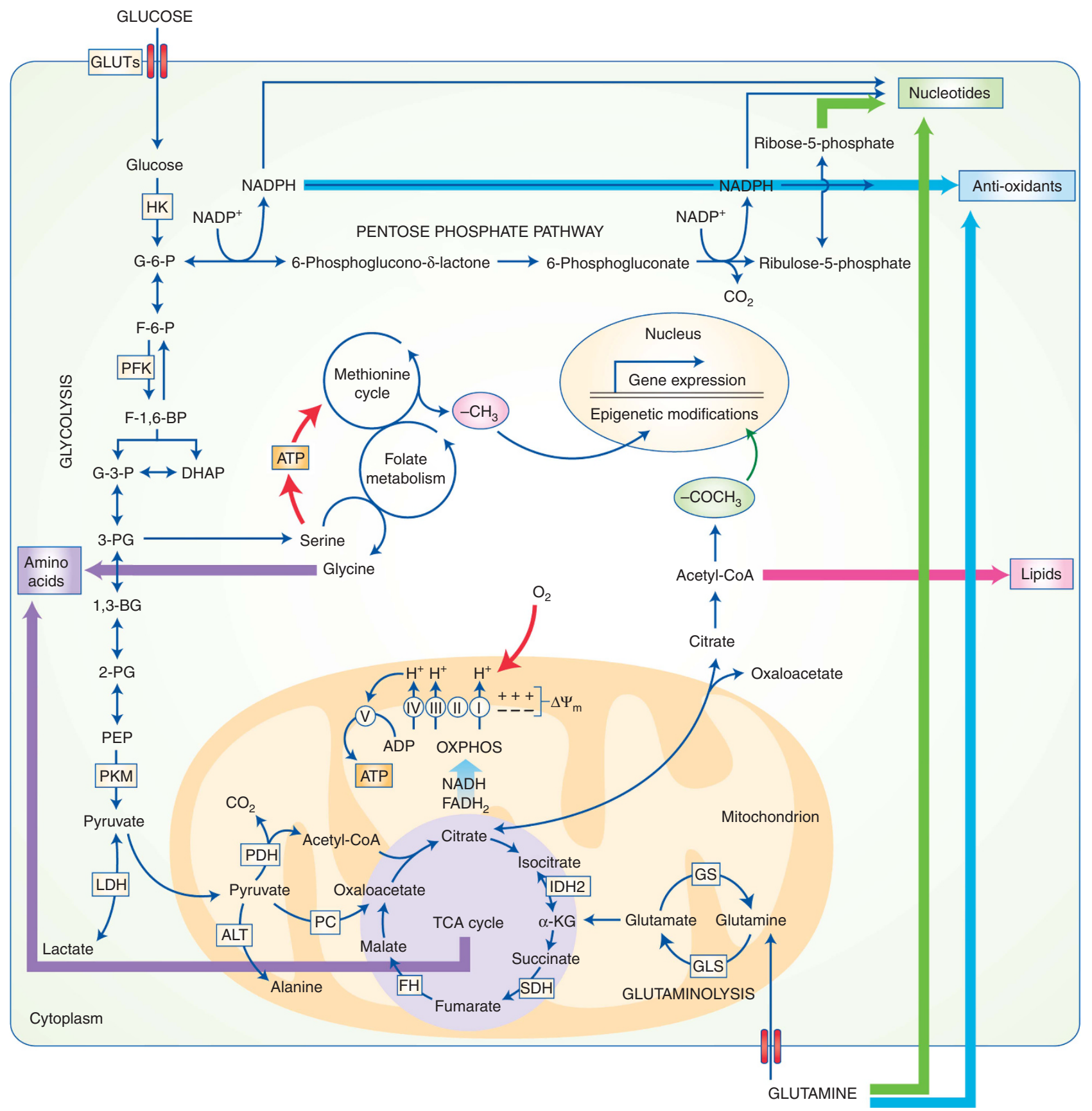

Figure 1. Overview of pathways implicated in cancer metabolism. Key enzymes are shown in white boxes. See text for details. Coloured block arrows denote contribution of metabolites to the respective cellular processes. $\Delta \Psi_{\mathrm{m}}$ denotes mitochondrial inner membrane potential. $-\mathrm{CH}_{3}$ and $-\mathrm{COCH}_{3}$ denote methyl and acetyl groups, respectively. ALT, alanine aminotransferase; 1,3-BG, 1,3-bisphosphoglycerate; DHAP, dihydroxyacetone phosphate; F-1,6-BP, fructose-1, 6-bisphosphate; F-6-P, fructose-6-phosphate; FH, fumarate hydratase; G-3-P, glyceraldehyde3-phosphate; G-6-P, glucose-6-phosphate; GLS, glutaminase, GS, glutamine synthetase; $\alpha$-KG, $\alpha$-ketoglutarate; HK, hexokinase; IDH, isocitrate dehydrogenase; LDH, lactate dehydrogenase; OXPHOS, oxidative phosphorylation; PC, pyruvate carboxylase; PDH, pyruvate dehydrogenase; PFK, phosphofructokinase; PKM, pyruvate kinase M isoform; PEP, phosphoenolpyruvate; 2-PG, 2-phosphoglycerate; 3-PG, 3-phosphoglycerate; ROS, reactive oxygen species; SDH, succinate dehydrogenase.

loses one carbon as $\mathrm{CO}_{2}$ and is converted to acetyl-coA by pyruvate dehydrogenase (PDH). Carbon metabolism in the TCA cycle can further provide metabolic intermediates for biosynthesis of lipids and amino acids, which, in addition to protein, are also precursors for nucleotides and glutathione. Furthermore, the TCA cycle concomitantly produces reducing power in the form of $\mathrm{NADH}$ and $\mathrm{FADH}_{2}$ to generate the proton motive force across the inner mitochondrial membrane required for ATP synthesis (DeBerardinis and Chandel, 2016).
A prevailing picture is that, in tumours, a higher fraction of glucose carbons is diverted away from mitochondria and converted to lactate by lactate dehydrogenase (LDH), a phenomenon referred to as the Warburg effect. Decreased catabolism of glucose in mitochondria had initially been attributed to mitochondrial dysfunction, raising the apparent paradox of how cancer cells can cope with a metabolic state that yields less energy per glucose molecule. However, there is little evidence that ATP is limiting for the growth of cancer cells (Israelsen and Vander 
Heiden, 2010) and, with the exception of tumours that harbour mutations in mitochondrial metabolic enzymes (such as succinate dehydrogenase, fumarate hydratase or isocitrate dehydrogenase), mitochondrial function is not only intact but also required for the growth of some tumours studied to date (Zong et al, 2016). The significance of the Warburg effect is not entirely understood, but is likely to be multi-dimensional. Computational modelling suggests that it may reflect a metabolic mode that combines efficiency for biomass and energy production, while affording cancer cells the necessary flexibility that allows them to adapt against various stresses (Shlomi et al, 2011; Keibler et al, 2016). Regardless, decreased entry of glucose carbons into the TCA cycle, in combination with the efflux of its intermediates into biosynthetic processes, imposes a need for topping up ('anaplerosis') the TCA cycle by carbon sources other than glucose.

Various nutrients have been implicated in TCA cycle anaplerosis. Among several amino acids that can be catabolised thought the TCA cycle, glutamine has long been considered the major anaplerotic source primarily due to its high abundance in the mammalian blood relative to other amino acids. Consistent with this, tumours that are not FDG-PET avid, may take up more glutamine as a complementary nutrient source (Lieberman et al, 2011)

During cell division, doubling of cellular mass imposes a need for carbon and nitrogen required to synthesise new biomolecules (Lunt and Vander Heiden, 2011). Together, increased glucose and glutamine consumption by tumours have been proposed to provide carbon and nitrogen precursors to sustain the biosynthesis of building blocks required for proliferation. However, a recurring observation in cultured cells is that a significant fraction of glucose or glutamine carbons is excreted as lactate (DeBerardinis et al, 2007; Hosios et al, 2016), which is not conducive to carbon preservation. Furthermore, a systematic tracing of glucose and glutamine carbons into biomass revealed that each contribute $<10 \%$ to total cell mass carbons in proliferating cultured cells (Hosios et al, 2016; Keibler et al, 2016). These observations suggest that the functions of glucose and glutamine catabolism may extend beyond a role as providers of atoms for other metabolites.

In addition to carbons and nitrogens, biosynthetic processes require energy and reducing power provided by ATP and pyridine nucleotides, respectively. In the process of being catabolised, glucose and glutamine transfer electrons to nicotinamide adenine dinucleotide $\left(\mathrm{NAD}^{+}\right)$and its cognate phosphorylated form $\mathrm{NADP}^{+}$, to produce $\mathrm{NADH}$ and $\mathrm{NADPH}$, respectively. For the synthesis of a simple lipid molecule, more glucose needs to be consumed to provide enough NADPH compared with the amount of glucose that provides the required carbons or ATP (Vander Heiden et al, 2009). Isotopic labelling studies support the notion that a significant fraction of cellular NADPH that contributes to lipid synthesis can be provided by glucose and glutamine (DeBerardinis et al, 2007; Fan et al, 2014; Lewis et al, 2014). Furthermore, despite the intimate link between the glucose and glutamine-fuelled TCA cycle and mitochondrial membrane potential in the context of ATP production, the cellular functions of these processes can be distinguished. Whereas TCA cycle activity sustains histone acetylation by incompletely understood mechanisms, mitochondrial membrane potential independently allows generation of reactive oxygen species (ROS) that, at low levels, can promote proliferation (Martinez-Reyes et al, 2016). This adds to an increasing body of work pointing to important roles for both glucose and glutamine in the maintenance of cellular redox balance and in providing precursors for epigenetic modifications, in addition to their contribution in sustaining the supply of metabolic intermediates for biosynthetic reactions.
THE TUMOUR MICROENVIRONMENT INFLUENCES CANCER CELL METABOLISM

Cellular metabolites have vastly diverse physicochemical properties, thereby necessitating the combination of various analytical methods for their detection and quantification. In some cases, the presence of a specific metabolite may inform of the metabolic state of a tumour; however, it is not always straightforward to infer the activity of specific metabolic pathways from the measurement of metabolite abundances alone (Buescher et al, 2015). The use of stable isotope tracers has been pivotal in analysing how specific metabolites are catabolised through various pathways by following the distribution of the labelled element in other molecules.

Administration of ${ }^{13} \mathrm{C}$-labelled glucose in human lung cancer patients identified increased contribution of glucose carbons to the TCA cycle, as well as lactate compared with non-cancerous extra-tumoral tissue (Sellers et al, 2015; Hensley et al, 2016). Interestingly, both pyruvate carboxylase (PC) and $\mathrm{PDH}$ can catalyse the entry of pyruvate into the TCA cycle, but the relative contribution of PDH exceeds that of PC (Hensley et al, 2016). Similarly, PDH was found to be essential for the growth of autochthonous lung tumours driven by oncogenic Ras in mice (Davidson et al, 2016). High-glucose catabolism in mitochondria through PC has also been observed in human glioblastoma tumours of diverse genetic backgrounds (Marin-Valencia et al, 2012). In all these cases, glutamine catabolism contributed little to the TCA cycle and cells from the respective tumours were resilient to glutamine withdrawal or inhibition of glutaminolysis. These data also resonate with observations of increased flux through PC in tumours that harbour TCA cycle enzyme mutations (Cardaci et al, 2015), or following genetic ablation of glutamine-dependent anaplerosis (Cheng et al, 2011). The reciprocal relationship between PC and glutamine catabolism through the TCA cycle reflects the importance of anaplerosis for sustaining TCA cycle functions.

In some tumour settings, decreased reliance on anaplerosis from exogenous glutamine is associated with the ability of these tumours to synthesise glutamine from glucose. Efflux of glucose carbons towards glutamine synthesis would also explain the co-existence of $\mathrm{PC}$ and PDH to provide both substrates required for citrate synthase (OAA and acetyl-coA) and maintain TCA cycle activity. Curiously, glutamine synthesis seems to operate in parallel to increased uptake of glutamine from the surrounding milieu, although the contribution of circulating glutamine to the latter may differ depending on the experimental model (Marin-Valencia et al, 2012; Tardito et al, 2015). Regardless, this evidence suggests that glutamine catabolism in pathways other than the TCA cycle remains important for the growth of tumours that oxidise glucose to $\mathrm{CO}_{2}$, in particular for providing nitrogens for de novo purine biosynthesis (Tardito et al, 2015).

The balance between glutamine synthesis and production is determined, to a certain degree, by the genetic background of the tumour. Mouse liver tumours induced by the Met oncogene synthesise glutamine, whereas Myc-induced liver tumours consume glutamine (Yuneva et al, 2012). In contrast, Myc-induced tumours in the mouse lung exhibit net glutamine synthesis. These differences may reflect an influence of the tissue and cell type from which tumours originate on whether specific metabolic gene loci can be expressed (Hoadley et al, 2014). However, in human lung tumours from the same patient, heterogeneity in their ability to oxidise glucose correlates better with the perfusion status of each tumour than its genetic background (Hensley et al, 2016). Notably, in an orthotopic mouse mammary gland tumour model, metastases in the lung exhibited increased reliance on PC-dependent anaplerosis compared with the primary tumour in vivo. Estimates of mitochondrial pyruvate concentrations based on the distribution 
of isotopic labelling patterns and metabolic modelling, hinted that this behaviour could arise from increased intracellular pyruvate concentrations that fall within the optimal range for PC activity (Christen et al, 2016). In cultured cells, increased extracellular pyruvate concentrations led to proportional increases in intracellular pyruvate, supporting the notion that substrate availability at the metastatic site is one factor through which the niche influences the metabolic signature of a tumour. Direct evidence that the microenvironment modulates tumour metabolism in a manner that is epistatic over its genetic background was provided in experiments where mouse lung cancer cells were isolated, cultured under standard conditions and re-introduced back into animals. These cells showed a propensity to excrete glucose-derived lactate and relied more on glutamine anaplerosis in contrast to the tumours they were derived from, which showed high-glucose oxidation and low-glutamine anaplerosis of the TCA cycle in vivo. When these cells were re-implanted into mouse lungs, they recovered the metabolic characteristics of the original tumours (Davidson et al, 2016).

Taken together, these observations shed fresh light into the use of glucose and glutamine in different autochthonous models of cancer and suggest that the metabolism of cancer cells is malleable to factors in their environment.

METABOLIC ADAPTATION TO LIMITING OXYGEN AND NUTRIENT CONCENTRATIONS

Remodelling of tissues during tumour development involves the convergence of various cell types, including fibroblasts, immune cells and endothelial cells (Junttila and de Sauvage, 2013) each with varying metabolic requirements (Ghesquiere et al, 2014). This combined with changes in nutrient and oxygen concentrations due to the dynamics of vasculature as tumours increase in mass, shape the tumour metabolic landscape in a complex manner that involves both cell-autonomous and non cell-autonomous mechanisms.

It is not entirely clear how tumours cope with low nutrient and oxygen concentrations between the time such deficits are sensed, suitable cellular responses are elicited and new vasculature is ultimately established. Early responses to acute drops in oxygen tension are mediated by changes in mitochondrial metabolism and, in particular, the generation of ROS (Chandel et al, 1998; Figure 2).

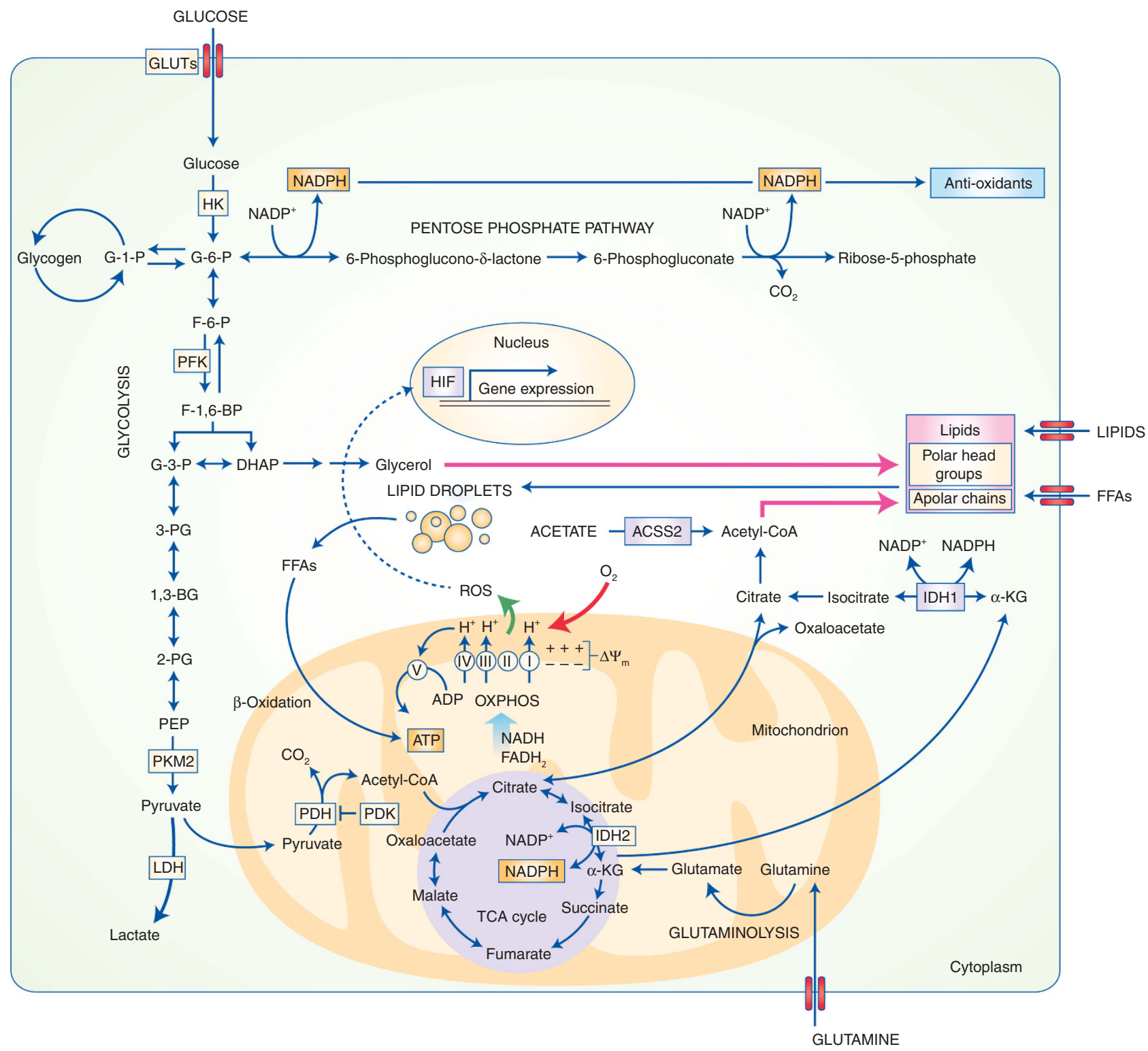

Figure 2. Overview of key metabolic pathways implicated in the response of cancer cells to low oxygen conditions. See text for details. ACSS2, Acetyl-CoA synthase isoform 2; HIF, hypoxia-inducible factor; FFAs, free fatty acids; other abbreviations are as in Figure 1. 
However, ROS can also react with various biomolecules, so tumour cells employ various mechanisms to maintain ROS homoeostasis. NADPH is central to the ability of cells to control ROS through its use for re-generating antioxidants such as glutathione. Deuterium tracing analyses revealed a significant contribution of glucose to NADPH production via the pentose phosphate pathway (PPP) for anti-oxidant functions (Fan et al, 2014). Oncogenes that activate the phosphoinositide-3-kinase pathway lead to increased glucose uptake and utilisation through the PPP to produce NADPH, and support survival following an acute increase in ROS associated with matrix detachment (Schafer et al, 2009), a cardinal feature of transformed cells. In hypoxia, glucose utilisation through the PPP can be promoted by direct modification of metabolic enzymes by ROS (Anastasiou et al, 2011) or glycosylation (Yi et al, 2012). In some settings, the anti-oxidant roles of glucose catabolism in hypoxia involve its turnover through glycogen, a polymer normally used to store glucose in specific healthy tissues, such as the liver and muscle. Glycogen accumulates in various cancer cell lines and hypoxic tumours, and inhibition of glycogen breakdown results in p53-induced senescence due to high levels of ROS (Favaro et al, 2012). What advantages utilisation of glycogen-derived glucose $v s$ exogenous glucose confer is not entirely clear. One possibility is that glycogen may provide a dedicated pool of PPP precursors that can be mobilised, perhaps more readily or at the required intracellular location and after only certain stimuli, while sparing free glucose for other functions.

Concomitantly, ROS, alongside inhibition of prolyl hydroxylases (PHDs), are essential for the long-term survival of hypoxic tumours by stabilising the hypoxia-inducible factor (HIF) family of transcription factors (Majmundar et al, 2010). Genes controlled by HIF1 include PDH kinase (PDK) and LDH. Inhibition of PDH activity through phosphorylation by $\mathrm{PDK}$, and expression of $\mathrm{LDH}$, lead to decreased entry of glucose-derived carbons into the TCA cycle and increased conversion of pyruvate into lactate (Papandreou et al, 2006; Figure 2).

To make glucose available for anti-oxidant functions in hypoxia, glutamine can sustain both ATP production (Fan et al, 2013) and lipid synthesis (Metallo et al, 2012). The latter is dependent on HIF through an incompletely understood mechanism that involves the reductive carboxylation of glutamine. A similar pathway for glutamine utilisation has also been observed during anchorageindependent growth (Jiang et al, 2016), lending further credence to a role for reductive glutamine metabolism under conditions that are relevant within the tumour microenvironment. In this setting, utilisation of glutamine reductively afforded cells an enhanced ability to detoxify mitochondrial ROS through NADPH produced by the mitochondrial IDH2 reaction. It is unclear whether this reconfiguration of glutamine metabolism also reflects an actual need for more lipids, as the role of de novo lipogenesis in hypoxic tumour growth and survival is likely context specific (Kamphorst et al, 2013). Furthermore, in various physiological settings when extracellular fatty acids are abundant, de novo lipogenesis is suppressed, suggesting that lipid metabolism may be further influenced by the availability of metabolic precursors also in hypoxia (Duarte et al, 2014; Yao et al, 2016).

Hypoxic cells accumulate lipid droplets that are essential for their survival, especially following re-oxygenation, where they have been proposed to provide an alternative-to-glycogen source of antioxidants, as well as help maintain ATP levels through fatty acid oxidation (Bensaad et al, 2014; Figure 2). Although the precise mechanism for the anti-oxidant function of lipid droplets in cancer cells is not clear, a cytoprotective role in hypoxia has been demonstrated in the developing Drosophila brain, where triglycerides in lipid droplets serve as a depot for polyunsaturated fatty acids, which are particularly susceptible to oxidative damage, thereby preventing the accumulation of harmful peroxidised lipids in cellular membranes (Bailey et al, 2015). Interestingly, overall fatty acid synthesis in hypoxia is suppressed (Metallo et al, 2012; Kamphorst et al, 2013; Bensaad et al, 2014); however, glucose contributes a large fraction of the glycerol backbone of polar lipids (Schug et al, 2015). If this were also the case for triglycerides, the main component of the lipid droplet core, it would help explain the increase in lipid droplet content.

On the other hand, increased uptake of exogenous free fatty acids by plasma membrane fatty acid carriers can provide the fatty acid moiety of lipids (Bensaad et al, 2014), and, in some experimental models, hypoxic cells preferentially deplete lysophospholipids from their media (Kamphorst et al, 2013). Furthermore, hypoxic cells can utilise acetate as the main source of acetyl-CoA for lipid synthesis due to the increased expression of acetyl-CoA synthase 2 (Kamphorst et al, 2014; Schug et al, 2015). An increased contribution of acetate to acetyl-coA and histones has also been observed in mouse liver cancer models (Comerford et al, 2014), orthotopically implanted human GBM tumours in mice, as well as human patients (Mashimo et al, 2014), which could reflect an increased presence of hypoxic regions in these tumours (Schug et al, 2015).

Deprivation of serum nutrients and hypoxia likely coincide in poorly vascularised tumours and can synergise in shaping the metabolic behaviour of hypoxic cells, although the relative sensitivity of cancer cells to these factors may be determined by both cell extrinsic (e.g., the relative diffusion of lipids $v s$ oxygen through tissues) and intrinsic mechanisms (e.g., the underlying oncogenic driver; Kamphorst et al, 2013; Li et al, 2013; Padanad et al, 2016; Peck et al, 2016). Emerging evidence points to an important role of the tumour stroma as a source of nutrients in the poorly irrigated tumour.

Increased autophagy in pancreatic stellate cells provides sufficient alanine to surrounding cancer cells to fuel TCA cycledependent biosynthetic processes (Sousa et al, 2016). Similarly, autophagy in primary cancer-associated fibroblasts (CAFs) results in elevated levels of dipeptides (two covalently bound amino acids; Chaudhri et al, 2013). The metabolic fate of dipeptides in vivo remains to be elucidated, however, CAFs derived from lung tumours that showed low glucose uptake had increased levels of dipeptides, suggesting that CAFs may provide an alternative source of carbon for neighbouring cancer cells. Metabolic synergism between cells in the tumour microenvironment where non-cancer cells are spared has also been observed. GBM tumours with low glutamine-synthesising capacity are found in the proximity of glutamine-synthesising astrocytes (Tardito et al, 2015).

High expression of transporters can facilitate the uptake of amino acids from the extracellular milieu and is associated with poor prognosis in some tumours (Kaira et al, 2012; Bhutia et al, 2015). Amino acids can also be derived from intact proteins taken up from the interstitial fluid. Cells transformed with oncogenic Ras have increased uptake of extracellular material via a process known as macropinocytosis (Commisso et al, 2013; Kamphorst et al, 2015). Intriguingly, although protein-derived carbons were found disseminated in various central metabolism pathways, the cytostatic effects of pharmacologically inhibited macropinocytosis could be overcome by glutamine metabolites. This finding may suggest that a primary function of macropinocytosis is to provide glutamine because, unlike its relative enrichment in the mammalian circulation, glutamine is not found at higher frequency compared with other amino acids in proteins (King and Jukes, 1969).

Whether and how biomolecules are mobilised from the surrounding tumour cells is relevant for further understanding and interfering with the metabolic interplay between the tumour stroma and cancer. Cancer cells are known to excrete microvesicles, such as exosomes, which contain various biomolecules, including RNA, DNA and proteins, and mediate intercellular 
communication (D'Souza-Schorey and Clancy, 2012). Emerging evidence suggests that metabolites may also be part of the exosomal cargo (Zhao et al, 2016). An alternative mechanism could involve the internalisation of entire cells, a recently described phenomenon named entosis (Overholtzer et al, 2007). On detachment from extracellular matrix, some cells are engulfed by their neighbours, wherein they are degraded in lysosomes, a prime site for aminoacid storage. The fate of the cellular degradation products is not clear; however, they could provide a readily available source of metabolic fuel. It is possible that amino acids are indiscriminately used as nutrient sources and analysis of carbon sources for biomass production points to a significant contribution of amino acids as biosynthetic precursors for protein (Hosios et al, 2016). However, there is ample evidence for specific, non-redundant functions of some amino acids.

Serine is a non-essential amino acid that can be synthesised from glucose, although some cells import it, depending on their genetic background. Cells lacking functional p53 are more sensitive to serine deprivation both in culture and when grown as xenografts in mice (Maddocks et al, 2013). Serine is important for de novo synthesis of ATP, which may have a broad influence on cellular metabolism. Among others, serine-derived ATP provides the adenosine moiety of S-adenosyl-methionine, a key methyl-donor for methylation reactions that regulate epigenetic gene expression (Locasale, 2013; Figure 1). Serine catabolism through the same pathway also provides a significant source of NADPH for lipid synthesis (Fan et al, 2014). Branched-chain amino acids have long been linked to proliferative signaling, as activators of the mechanistic target of rapamycin pathway. Branched-chain amino acid catabolism through branched chain amino acid amino transferases may also provide an alternative source of metabolic precursors to sustain glioblastoma proliferation (Tonjes et al, 2013).

Together, the observations above highlight potential roles of the tumour niche, and in particular fibroblasts, as a complementary source for alternative nutrients to those provided by the circulation. However, cancer cells may engage in further metabolic interplay with other cell types in their vicinity in a way that influences tumour progression.

INFLUENCE OF METABOLISM ON CELLULAR DYNAMICS IN THE TUMOUR MICROENVIRONMENT

The role of the immune system to tumorigenesis is complex, and although in some settings inflammation has a tumour-promoting role, it is also clear that evading recognition by the immune system is a cardinal feature of cancer. The metabolic needs of immune cells implicated in tumorigenesis vary widely depending both on their subtype and activation status (Pearce et al, 2013; O'Neill et al, 2016).

Tryptophan is a precursor for de novo synthesis of NAD (Figure 3A). The first step of tryptophan metabolism is catalysed by indoleamine diooxygenase or tryptophan dioxygenase (IDO and TDO, respectively), which produce $N$-formyl-kynurenine, a precursor of kynurenine. Kynurenine is an endogenous ligand for aryl hydrocarbon receptor (AhR), a transcription factor also known to respond to environmental toxins. In gliomas, high TDO expression and associated kynurenine levels lead to increased AhR activity to promote tumorigenesis (Opitz et al, 2011). In contrast, mouse liver cancer is promoted by suppression of tryptophan catabolism (Tummala et al, 2014). This was attributed to the decreased NAD production that results in suboptimal activity of the NAD-dependent DNA repair enzyme poly-ADP ribose polymerase.

The fact that both increased or decreased tryptophan catabolism are associated with tumorigenesis, albeit at different tissues, is seemingly contradictory. Intriguingly, in the same model of liver cancer, there is increased IL-17A due to infiltrating $T_{h} 17$ cells, which contributes to an inflammatory environment that promotes steatosis, a predisposing factor to hepatocellular carcinoma (Gomes et al, 2016). Aryl hydrocarbon receptor is essential for $\mathrm{T}_{\mathrm{h}} 17$ differentiation and tryptophan promotes $\mathrm{T}_{\mathrm{h}} 17$ differentiation in culture (Veldhoen et al, 2008; Veldhoen et al, 2009). It is possible that a reciprocal relationship exists between kynurenine and NAD production, where diversion of tryptophan carbons to kynurenine depletes precursors for NAD synthesis and vice versa. Alternatively, suppressed tryptophan catabolism may be occurring early enough in the HCC model, leading to increased available tryptophan thereby providing a favourable niche for $T_{h} 17$ differentiation (Figure 3A).

In activated $\mathrm{T}$ cells, PEP produced through glycolysis inhibits the sequestration of calcium in the endoplasmic reticulum (ER) by binding to and allosterically inhibiting sarcoplasmic/ER calcium ATPase (Figure 3B). This leads to a sustained increase in cytoplasmic calcium to activate NFAT, a transcription factor that mediates anti-tumour T-cell functions (Ho et al, 2015). In a mouse model of melanoma, glucose concentrations in the tumour interstitial fluid were 15 times lower than in the circulation due to high glycolysis by the tumour. Concomitantly, infiltrating tumour lymphocytes exhibited signs of glucose deprivation and decreased NFAT activity. Upregulation of PEP production in $\mathrm{T}$ cells by overexpression of PEP carboxykinase, preserved PEP levels under glucose-poor conditions and ameliorated tumour clearance. Intriguingly, signalling downstream of the PD-L1 receptor in cancer cells enhances tumour glycolysis (Chang et al, 2015), so immunotherapies targeting PD-L1 suppress tumour growth not only by enabling better tumour recognition by the immune system but also by interfering with tumour glycolysis.

The role of glucose metabolism in the stroma extends to endothelial cells, which are key components of new blood vessels that feed tumours. In diverse pathological settings, endothelial cell proliferation is accompanied by increased glycolysis that can be suppressed by inhibition of the glycolytic enzyme phosphofructokinase-2/fructose-2,6-bisphosphatase 3 (De Bock et al, 2013; Schoors et al, 2014). Phosphofructokinase-2/fructose-2,6-bisphosphatase 3-dependent glycolysis, and the ensuing production of ATP, is also required for essential cytoskeletal rearrangements of pioneer cells, known as tip cells, in newly forming vessels (De Bock et al, 2013; Cruys et al, 2016). In parallel, fatty acid oxidation, which could also potentially sustain ATP production, supports the synthesis of precursors in endothelial cells for nucleotide biosynthesis (Schoors et al, 2015).

These findings highlight the possibility that targeting metabolic pathways shared between cancer and stromal cells could provide a multi-pronged approach for cancer therapy. Nevertheless, they also illustrate that a deeper, systematic analysis of immune cell metabolism in various tumours would be required to evaluate the feasibility of this idea. For example, significant efforts have been invested in inhibiting glucose catabolism in tumours; however, limiting glucose uptake in tumours, instead, may be preferable, because it would be predicted to both undermine cancer metabolism, as well as restore the function of tumour-infiltrating $\mathrm{T}$ cells and endothelial cells. The latter could permit the maintenance of blood vessels necessary for the delivery of therapeutic agents to the tumours. Furthermore, although the above examples focus on $\mathrm{T}$ cells, given the importance of specific metabolic pathways on the function of almost every immune cell type studied to date, similar paradigms are likely applicable for other immune cell types. Ultimately, it is likely that the dynamics of nutrients in the tumour microenvironment, in addition to cell-intrinsic metabolic dependencies of immune cells may orchestrate the cellular profile of the stroma within each tumour. 
A

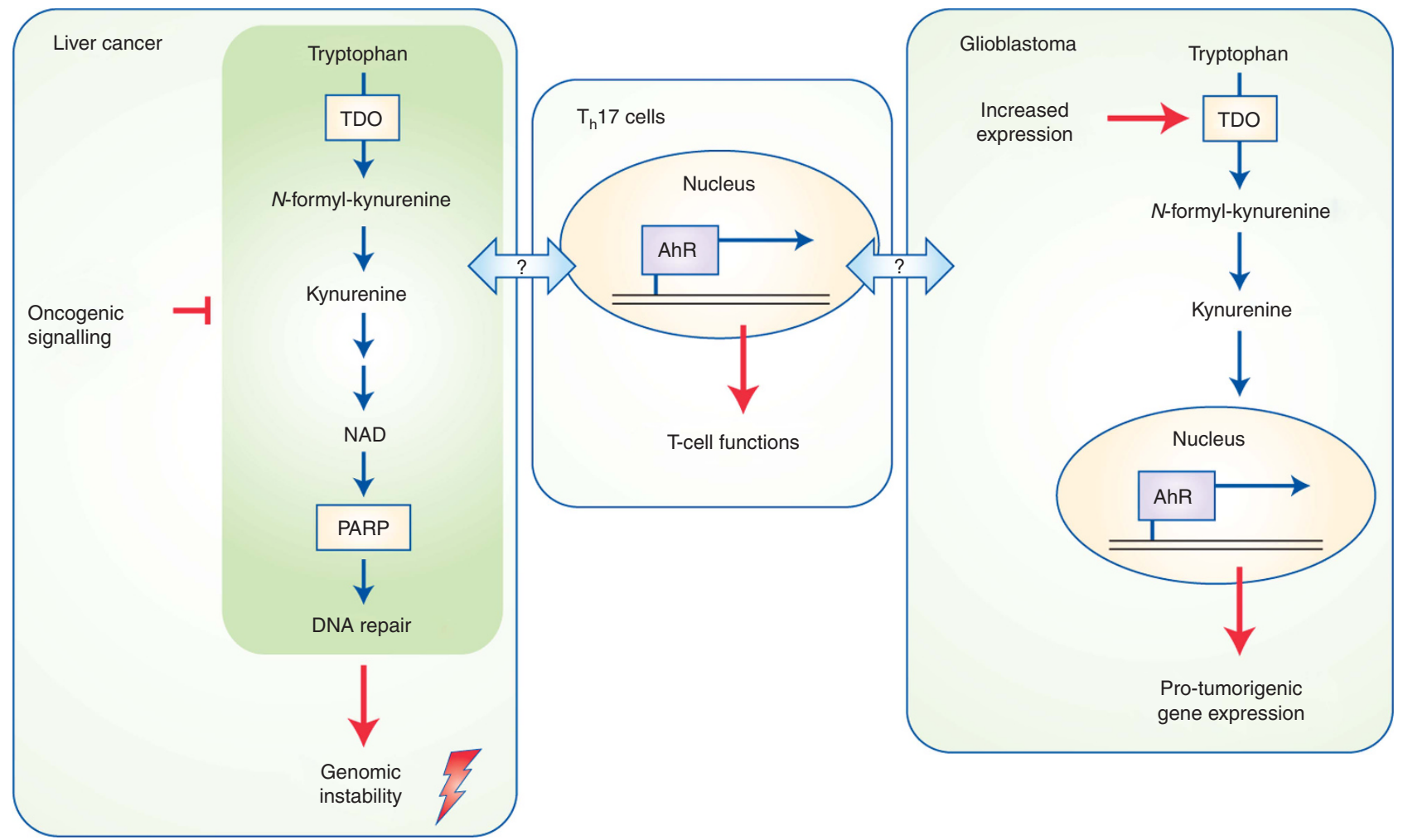

B

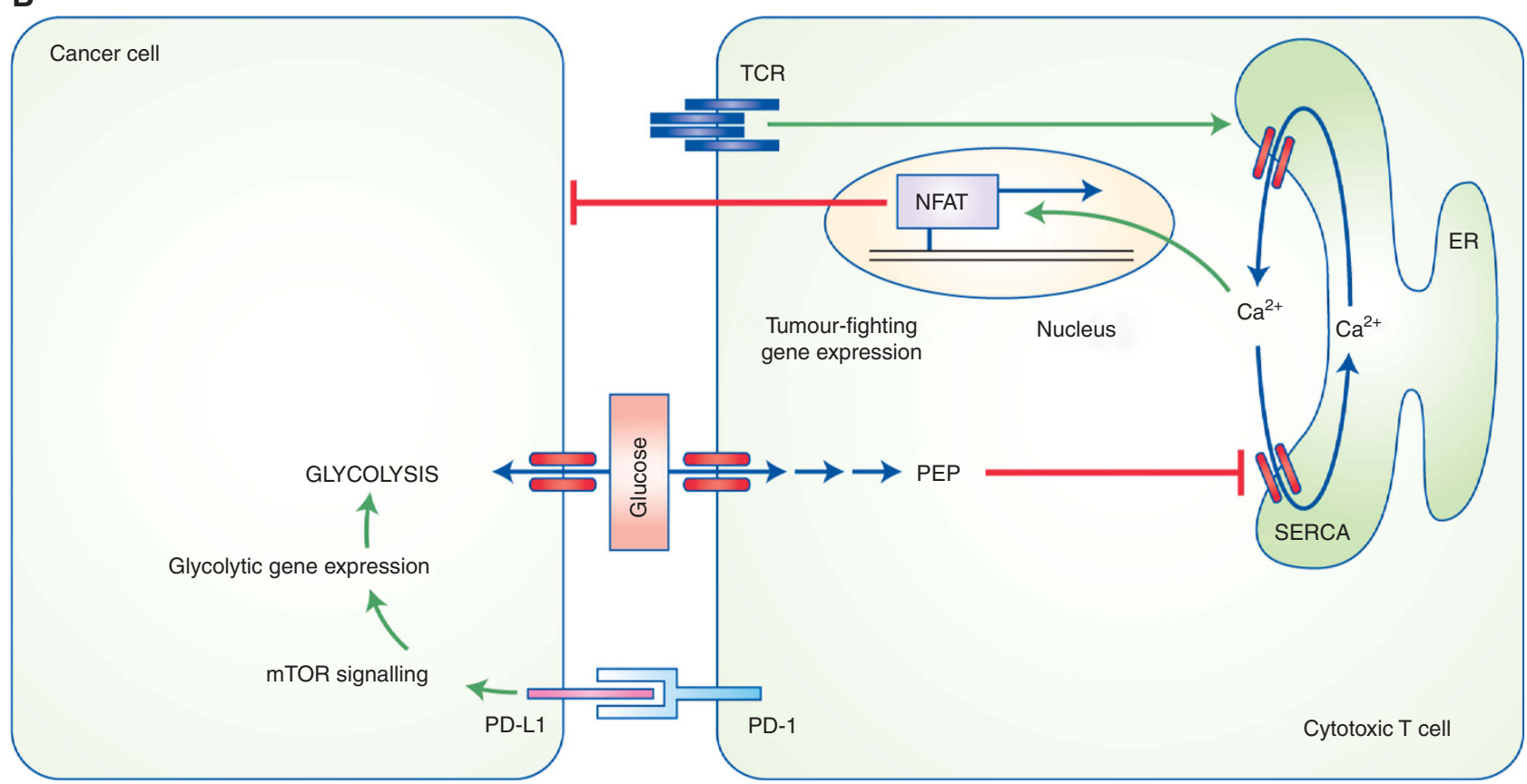

Figure 3. Paradigms of cancer-immune cell interactions. (A) Tryptophan metabolism yields the intermediate kynurenine, which promotes glioblastoma development by activating the aryl hydrocarbon receptor, a transcription factor that controls the expression of pro-tumorigenic genes. A downstream product of further kynurenine catabolism is NAD, which, among others, is an essential co-factor for the DNA repair enzyme poly-ADP ribose polymerase (PARP). Suppression of NAD synthesis by oncogenic signalling in liver tumours leads to increased genomic instability, thereby promoting tumorigenesis. $T_{h} 17$ cell differentiation can be influenced by tryptophan metabolites and $T_{h} 17$-mediated inflammation has been implicated in liver cancer. Whether tryptophan metabolism in cancer cells influences tumour progression by modulating immune cells remains to be seen. (B) Metabolic competition for glucose between cancer cells and tumour-infiltrating T cells. In the proximity of highly glycolytic cancer cells, T cells fail to sustain cytoplasmic calcium levels necessary to activate the NFAT transcription factor, which mediates anti-tumour responses of T cells. The immunosuppressive molecule PD-L1 in cancer cells, may further promote glucose metabolism by signalling through the mechanistic target of rapamycin (mTOR) pathway, in addition to suppressing T cells via interaction with PD-1. ER, endoplasmic reticulum; NFAT, nuclear factor of activated T cells; PD-1, programmed cell death protein 1; PD-L1, PD ligand 1; PEP; phosphoenolpyruvate; SERCA, sarcoplasmic/ endoplasmic reticulum calcium ATPase; TCR, T-cell receptor; TDO, tryptophan dioxygenase. 


\section{SUMMARY AND PERSPECTIVES}

The microenvironments of various tumours are heterogeneous, partly because they integrate the varying metabolic behaviours of multiple cell types. Constant recruitment and turnover of these cells in conjunction with distinct cancer cell metabolic needs influence the dynamics of tumour metabolism through the various stages of cancer development. As a result, although, clearly, some of the metabolic characteristics of cancer cells are determined by the underlying genetic background, it is hard to conceive a single metabolic profile even for one type of cancer in the context of a constantly evolving metabolic landscape within the tumour microenvironment.

Studies of cancer metabolism in living higher organisms are uncovering the influence of metabolic interactions with the proximal environment. In addition, these experimental systems can reveal the influence of distal factors, such as nutrient metabolism via organs other than where the tumour is growing, or the resident microflora, the role of which in tumorigenesis is indicated by epidemiological evidence. At the same time, although yielding a physiological picture of tumour metabolism, these factors further convolute the process of pinpointing the source of specific metabolic phenotypes (Pichumani et al, 2016), and this may complicate the design of strategies for targeted therapeutics.

The development of imaging methods to study metabolism at the single-cell level in autochthonous settings will be invaluable in overcoming such limitations. In parallel, as we better understand the microenvironmental factors that influence the metabolic behaviours of cancer cells in physiological settings, there is a persistent incentive to successfully translate this knowledge into meaningful cell culture conditions. The advantages of using primary tumour cells isolated from mouse models or patients can be further broadened by mimicking tumour microenvironment factors, such as oxygen, nutrient and extracellular matrix conditions, which, in some settings, allow the recapitulation of in vivo metabolic behaviours also in vitro (Bensaad et al, 2014; Tardito et al, 2015). Furthermore, screening, testing and validation of new therapeutics can be tremendously expedited and scaled up in cultured cells.

Finally, appreciating the metabolic needs of both epithelial and stromal cells not only in fully-formed, proliferative tumours, but throughout tumour development may expand the scope of targeting metabolism for therapeutic purposes also for cancer prevention.

\section{ACKNOWLEDGEMENTS}

Work in the author's lab related to the content of this review is supported by European Union's Horizon 2020 research and innovation programme under the Marie Skłodowska-Curie grant agreement no. 642738; and by the Francis Crick Institute which receives its core funding from Cancer Research UK (FC001033), the UK Medical Research Council (FC001033) and the Wellcome Trust (FC001033).

\section{CONFLICT OF INTEREST}

The author declares no conflict of interest.

\section{REFERENCES}

Anastasiou D, Poulogiannis G, Asara JM, Boxer MB, Jiang JK, Shen M,

Bellinger G, Sasaki AT, Locasale JW, Auld DS, Thomas CJ, Vander Heiden MG,
Cantley LC (2011) Inhibition of pyruvate kinase M2 by reactive oxygen species contributes to cellular antioxidant responses. Science 334: $1278-1283$.

Bailey AP, Koster G, Guillermier C, Hirst EM, MacRae JI, Lechene CP, Postle AD, Gould AP (2015) Antioxidant role for lipid droplets in a stem cell niche of Drosophila. Cell 163: 340-353.

Bensaad K, Favaro E, Lewis CA, Peck B, Lord S, Collins JM, Pinnick KE, Wigfield S, Buffa FM, Li JL, Zhang Q, Wakelam MJ, Karpe F, Schulze A, Harris AL (2014) Fatty acid uptake and lipid storage induced by HIF-1alpha contribute to cell growth and survival after hypoxiareoxygenation. Cell Rep 9: 349-365.

Bhutia YD, Babu E, Ramachandran S, Ganapathy V (2015) Amino Acid transporters in cancer and their relevance to 'glutamine addiction': novel targets for the design of a new class of anticancer drugs. Cancer Res 75: $1782-1788$.

Buescher JM, Antoniewicz MR, Boros LG, Burgess SC, Brunengraber H, Clish CB, DeBerardinis RJ, Feron O, Frezza C, Ghesquiere B, Gottlieb E, Hiller K, Jones RG, Kamphorst JJ, Kibbey RG, Kimmelman AC, Locasale JW, Lunt SY, Maddocks OD, Malloy C, Metallo CM, Meuillet EJ, Munger J, Noh K, Rabinowitz JD, Ralser M, Sauer U, Stephanopoulos G, St-Pierre J, Tennant DA, Wittmann C, Vander Heiden MG, Vazquez A, Vousden K, Young JD, Zamboni N, Fendt SM (2015) A roadmap for interpreting (13)C metabolite labeling patterns from cells. Curr Opin Biotechnol 34: 189-201.

Cardaci S, Zheng L, MacKay G, van den Broek NJ, MacKenzie ED, Nixon C, Stevenson D, Tumanov S, Bulusu V, Kamphorst JJ, Vazquez A, Fleming S, Schiavi F, Kalna G, Blyth K, Strathdee D, Gottlieb E (2015) Pyruvate carboxylation enables growth of SDH-deficient cells by supporting aspartate biosynthesis. Nat Cell Biol 17: 1317-1326.

Chandel NS, Maltepe E, Goldwasser E, Mathieu CE, Simon MC, Schumacker PT (1998) Mitochondrial reactive oxygen species trigger hypoxia-induced transcription. Proc Natl Acad Sci USA 95: 11715-11720.

Chang CH, Qiu J, O'Sullivan D, Buck MD, Noguchi T, Curtis JD, Chen Q, Gindin M, Gubin MM, van der Windt GJ, Tonc E, Schreiber RD, Pearce EJ, Pearce EL (2015) Metabolic competition in the tumor microenvironment is a driver of cancer progression. Cell 162: 1229-1241.

Chaudhri VK, Salzler GG, Dick SA, Buckman MS, Sordella R, Karoly ED, Mohney R, Stiles BM, Elemento O, Altorki NK, McGraw TE (2013) Metabolic alterations in lung cancer-associated fibroblasts correlated with increased glycolytic metabolism of the tumor. Mol Cancer Res 11: 579-592.

Cheng T, Sudderth J, Yang C, Mullen AR, Jin ES, Mates JM, DeBerardinis RJ (2011) Pyruvate carboxylase is required for glutamine-independent growth of tumor cells. Proc Natl Acad Sci USA 108: 8674-8679.

Christen S, Lorendeau D, Schmieder R, Broekaert D, Metzger K, Veys K, Elia I, Buescher JM, Orth MF, Davidson SM, Grunewald TG, De Bock K, Fendt SM (2016) Breast cancer-derived lung metastases show increased pyruvate carboxylase-dependent anaplerosis. Cell Rep 17: 837-848.

Comerford SA, Huang Z, Du X, Wang Y, Cai L, Witkiewicz AK, Walters H, Tantawy MN, Fu A, Manning HC, Horton JD, Hammer RE, McKnight SL, Tu BP (2014) Acetate dependence of tumors. Cell 159: 1591-1602.

Commisso C, Davidson SM, Soydaner-Azeloglu RG, Parker SJ, Kamphorst JJ, Hackett S, Grabocka E, Nofal M, Drebin JA, Thompson CB, Rabinowitz JD, Metallo CM, Vander Heiden MG, Bar-Sagi D (2013) Macropinocytosis of protein is an amino acid supply route in Ras-transformed cells. Nature 497: 633-637.

Cruys B, Wong BW, Kuchnio A, Verdegem D, Cantelmo AR, Conradi LC, Vandekeere S, Bouche A, Cornelissen I, Vinckier S, Merks RM, Dejana E, Gerhardt H, Dewerchin M, Bentley K, Carmeliet P (2016) Glycolytic regulation of cell rearrangement in angiogenesis. Nat Commun 7: 12240.

D'Souza-Schorey C, Clancy JW (2012) Tumor-derived microvesicles: shedding light on novel microenvironment modulators and prospective cancer biomarkers. Genes Dev 26: 1287-1299.

Davidson SM, Papagiannakopoulos T, Olenchock BA, Heyman JE, Keibler MA, Luengo A, Bauer MR, Jha AK, O’Brien JP, Pierce KA, Gui DY, Sullivan LB, Wasylenko TM, Subbaraj L, Chin CR, Stephanopolous G, Mott BT, Jacks T, Clish CB, Vander Heiden MG (2016) Environment impacts the metabolic dependencies of ras-driven non-small cell lung cancer. Cell Metab 23: 517-528.

De Bock K, Georgiadou M, Schoors S, Kuchnio A, Wong BW, Cantelmo AR, Quaegebeur A, Ghesquiere B, Cauwenberghs S, Eelen G, Phng LK, Betz I, Tembuyser B, Brepoels K, Welti J, Geudens I, Segura I, Cruys B, Bifari F, Decimo I, Blanco R, Wyns S, Vangindertael J, Rocha S, Collins RT, 
Munck S, Daelemans D, Imamura H, Devlieger R, Rider M, Van Veldhoven PP, Schuit F, Bartrons R, Hofkens J, Fraisl P, Telang S, Deberardinis RJ, Schoonjans L, Vinckier S, Chesney J, Gerhardt H, Dewerchin M, Carmeliet P (2013) Role of PFKFB3-driven glycolysis in vessel sprouting. Cell 154: 651-663.

DeBerardinis RJ, Chandel NS (2016) Fundamentals of cancer metabolism. Sci Adv 2: e1600200.

DeBerardinis RJ, Mancuso A, Daikhin E, Nissim I, Yudkoff M, Wehrli S, Thompson CB (2007) Beyond aerobic glycolysis: transformed cells can engage in glutamine metabolism that exceeds the requirement for protein and nucleotide synthesis. Proc Natl Acad Sci USA 104: 19345-19350.

Duarte JA, Carvalho F, Pearson M, Horton JD, Browning JD, Jones JG, Burgess SC (2014) A high-fat diet suppresses de novo lipogenesis and desaturation but not elongation and triglyceride synthesis in mice. J Lipid Res 55: 2541-2553.

Elia I, Schmieder R, Christen S, Fendt SM (2016) Organ-specific cancer metabolism and its potential for therapy. Handb Exp Pharmacol 233: 321-353.

Fan J, Kamphorst JJ, Mathew R, Chung MK, White E, Shlomi T, Rabinowitz JD (2013) Glutamine-driven oxidative phosphorylation is a major ATP source in transformed mammalian cells in both normoxia and hypoxia. Mol Syst Biol 9: 712.

Fan J, Ye J, Kamphorst JJ, Shlomi T, Thompson CB, Rabinowitz JD (2014) Quantitative flux analysis reveals folate-dependent NADPH production. Nature 510: 298-302.

Favaro E, Bensaad K, Chong MG, Tennant DA, Ferguson DJ, Snell C, Steers G, Turley H, Li JL, Gunther UL, Buffa FM, McIntyre A, Harris AL (2012) Glucose utilization via glycogen phosphorylase sustains proliferation and prevents premature senescence in cancer cells. Cell Metab 16: 751-764.

Galluzzi L, Kepp O, Vander Heiden MG, Kroemer G (2013) Metabolic targets for cancer therapy. Nat Rev Drug Discov 12: 829-846.

Ghesquiere B, Wong BW, Kuchnio A, Carmeliet P (2014) Metabolism of stromal and immune cells in health and disease. Nature 511: 167-176.

Gomes AL, Teijeiro A, Buren S, Tummala KS, Yilmaz M, Waisman A, Theurillat JP, Perna C, Djouder N (2016) Metabolic inflammationassociated IL-17A causes non-alcoholic steatohepatitis and hepatocellular carcinoma. Cancer Cell 30: 161-175.

Hensley CT, Faubert B, Yuan Q, Lev-Cohain N, Jin E, Kim J, Jiang L, Ko B, Skelton R, Loudat L, Wodzak M, Klimko C, McMillan E, Butt Y, Ni M, Oliver D, Torrealba J, Malloy CR, Kernstine K, Lenkinski RE, DeBerardinis RJ (2016) Metabolic heterogeneity in human lung tumors. Cell 164: 681-694.

Ho PC, Bihuniak JD, Macintyre AN, Staron M, Liu X, Amezquita R, Tsui YC, Cui G, Micevic G, Perales JC, Kleinstein SH, Abel ED, Insogna KL, Feske S, Locasale JW, Bosenberg MW, Rathmell JC, Kaech SM (2015) Phosphoenolpyruvate is a metabolic checkpoint of anti-tumor T cell responses. Cell 162: 1217-1228.

Hoadley KA, Yau C, Wolf DM, Cherniack AD, Tamborero D, Ng S, Leiserson MD, Niu B, McLellan MD, Uzunangelov V, Zhang J, Kandoth C, Akbani R, Shen H, Omberg L, Chu A, Margolin AA, Van't Veer LJ, Lopez-Bigas N, Laird PW, Raphael BJ, Ding L, Robertson AG, Byers LA, Mills GB, Weinstein JN, Van Waes C, Chen Z, Collisson EA. Cancer Genome Atlas Research, N.Benz CC, Perou CM, Stuart JM (2014) Multiplatform analysis of 12 cancer types reveals molecular classification within and across tissues of origin. Cell 158: 929-944.

Hosios AM, Hecht VC, Danai LV, Johnson MO, Rathmell JC, Steinhauser ML, Manalis SR, Vander Heiden MG (2016) Amino acids rather than glucose account for the majority of cell mass in proliferating mammalian cells. Dev Cell 36: 540-549.

Israelsen WJ, Vander Heiden MG (2010) ATP consumption promotes cancer metabolism. Cell 143: 669-671.

Jiang L, Shestov AA, Swain P, Yang C, Parker SJ, Wang QA, Terada LS, Adams ND, McCabe MT, Pietrak B, Schmidt S, Metallo CM, Dranka BP, Schwartz B, DeBerardinis RJ (2016) Reductive carboxylation supports redox homeostasis during anchorage-independent growth. Nature 532: 255-258.

Junttila MR, de Sauvage FJ (2013) Influence of tumour micro-environment heterogeneity on therapeutic response. Nature 501: 346-354.

Kaira K, Sunose Y, Arakawa K, Ogawa T, Sunaga N, Shimizu K, Tominaga H, Oriuchi N, Itoh H, Nagamori S, Kanai Y, Segawa A, Furuya M, Mori M, Oyama T, Takeyoshi I (2012) Prognostic significance of L-type amino-acid transporter 1 expression in surgically resected pancreatic cancer. $\mathrm{Br} \mathrm{J}$ Cancer 107: 632-638.
Kamphorst JJ, Chung MK, Fan J, Rabinowitz JD (2014) Quantitative analysis of acetyl-CoA production in hypoxic cancer cells reveals substantial contribution from acetate. Cancer Metab 2: 23.

Kamphorst JJ, Cross JR, Fan J, de Stanchina E, Mathew R, White EP, Thompson CB, Rabinowitz JD (2013) Hypoxic and Ras-transformed cells support growth by scavenging unsaturated fatty acids from lysophospholipids. Proc Natl Acad Sci USA 110: 8882-8887.

Kamphorst JJ, Nofal M, Commisso C, Hackett SR, Lu W, Grabocka E, Vander Heiden MG, Miller G, Drebin JA, Bar-Sagi D, Thompson CB, Rabinowitz JD (2015) Human pancreatic cancer tumors are nutrient poor and tumor cells actively scavenge extracellular protein. Cancer Res $\mathbf{7 5}$ : 544-553.

Keibler MA, Wasylenko TM, Kelleher JK, Iliopoulos O, Vander Heiden MG, Stephanopoulos G (2016) Metabolic requirements for cancer cell proliferation. Cancer Metab 4: 16.

King JL, Jukes TH (1969) Non-Darwinian evolution. Science 164: 788-798.

Lewis CA, Parker SJ, Fiske BP, McCloskey D, Gui DY, Green CR, Vokes NI, Feist AM, Vander Heiden MG, Metallo CM (2014) Tracing compartmentalized NADPH metabolism in the cytosol and mitochondria of mammalian cells. Mol Cell 55: 253-263.

Li L, Wang C, Calvisi DF, Evert M, Pilo MG, Jiang L, Yuneva M, Chen X (2013) SCD1 Expression is dispensable for hepatocarcinogenesis induced by AKT and Ras oncogenes in mice. PLoS One 8: e75104.

Lieberman BP, Ploessl K, Wang L, Qu W, Zha Z, Wise DR, Chodosh LA, Belka G, Thompson CB, Kung HF (2011) PET imaging of glutaminolysis in tumors by $18 \mathrm{~F}-(2 \mathrm{~S}, 4 \mathrm{R}) 4$-fluoroglutamine. J Nucl Med 52: 1947-1955.

Locasale JW (2013) Serine, glycine and one-carbon units: cancer metabolism in full circle. Nat Rev Cancer 13: 572-583.

Lunt SY, Vander Heiden MG (2011) Aerobic glycolysis: meeting the metabolic requirements of cell proliferation. Annu Rev Cell Dev Biol 27: 441-464.

Maddocks OD, Berkers CR, Mason SM, Zheng L, Blyth K, Gottlieb E, Vousden KH (2013) Serine starvation induces stress and p53-dependent metabolic remodelling in cancer cells. Nature 493: 542-546.

Majmundar AJ, Wong WJ, Simon MC (2010) Hypoxia-inducible factors and the response to hypoxic stress. Mol Cell 40: 294-309.

Marin-Valencia I, Yang C, Mashimo T, Cho S, Baek H, Yang XL, Rajagopalan KN, Maddie M, Vemireddy V, Zhao Z, Cai L, Good L, Tu BP, Hatanpaa KJ, Mickey BE, Mates JM, Pascual JM, Maher EA, Malloy CR, Deberardinis RJ, Bachoo RM (2012) Analysis of tumor metabolism reveals mitochondrial glucose oxidation in genetically diverse human glioblastomas in the mouse brain in vivo. Cell Metab 15: 827-837.

Martinez-Reyes I, Diebold LP, Kong H, Schieber M, Huang H, Hensley CT, Mehta MM, Wang T, Santos JH, Woychik R, Dufour E, Spelbrink JN, Weinberg SE, Zhao Y, DeBerardinis RJ, Chandel NS (2016) TCA cycle and mitochondrial membrane potential are necessary for diverse biological functions. Mol Cell 61: 199-209.

Mashimo T, Pichumani K, Vemireddy V, Hatanpaa KJ, Singh DK, Sirasanagandla S, Nannepaga S, Piccirillo SG, Kovacs Z, Foong C, Huang Z, Barnett S, Mickey BE, DeBerardinis RJ, Tu BP, Maher EA, Bachoo RM (2014) Acetate is a bioenergetic substrate for human glioblastoma and brain metastases. Cell 159: 1603-1614.

Metallo CM, Gameiro PA, Bell EL, Mattaini KR, Yang J, Hiller K, Jewell CM, Johnson ZR, Irvine DJ, Guarente L, Kelleher JK, Vander Heiden MG, Iliopoulos O, Stephanopoulos G (2012) Reductive glutamine metabolism by IDH1 mediates lipogenesis under hypoxia. Nature 481: 380-384.

O’Neill LA, Kishton RJ, Rathmell J (2016) A guide to immunometabolism for immunologists. Nat Rev Immunol 16: 553-565.

Opitz CA, Litzenburger UM, Sahm F, Ott M, Tritschler I, Trump S, Schumacher T, Jestaedt L, Schrenk D, Weller M, Jugold M, Guillemin GJ, Miller CL, Lutz C, Radlwimmer B, Lehmann I, von Deimling A, Wick W, Platten M (2011) An endogenous tumour-promoting ligand of the human aryl hydrocarbon receptor. Nature 478: 197-203.

Overholtzer M, Mailleux AA, Mouneimne G, Normand G, Schnitt SJ, King RW, Cibas ES, Brugge JS (2007) A nonapoptotic cell death process, entosis, that occurs by cell-in-cell invasion. Cell 131: 966-979.

Padanad MS, Konstantinidou G, Venkateswaran N, Melegari M, Rindhe S, Mitsche M, Yang C, Batten K, Huffman KE, Liu J, Tang X, Rodriguez-Canales J, Kalhor N, Shay JW, Minna JD, McDonald J, Wistuba II, DeBerardinis RJ, Scaglioni PP (2016) Fatty acid oxidation mediated by acyl-CoA synthetase long chain 3 is required for mutant KRAS lung tumorigenesis. Cell Rep 16: 1614-1628. 
Papandreou I, Cairns RA, Fontana L, Lim AL, Denko NC (2006) HIF-1 mediates adaptation to hypoxia by actively downregulating mitochondrial oxygen consumption. Cell Metab 3: 187-197.

Pavlova NN, Thompson CB (2016) The emerging hallmarks of cancer metabolism. Cell Metab 23: 27-47.

Pearce EL, Poffenberger MC, Chang CH, Jones RG (2013) Fueling immunity: insights into metabolism and lymphocyte function. Science 342: 1242454

Peck B, Schug ZT, Zhang Q, Dankworth B, Jones DT, Smethurst E, Patel R, Mason S, Jiang M, Saunders R, Howell M, Mitter R, Spencer-Dene B, Stamp G, McGarry L, James D, Shanks E, Aboagye EO, Critchlow SE, Leung HY, Harris AL, Wakelam MJ, Gottlieb E, Schulze A (2016) Inhibition of fatty acid desaturation is detrimental to cancer cell survival in metabolically compromised environments. Cancer Metab 4: 6 .

Pichumani K, Mashimo T, Vemireddy V, Kovacs Z, Ratnakar J, Mickey B, Malloy CR, DeBerardinis RJ, Bachoo RM, Maher EA (2016) Hepatic gluconeogenesis influences (13)C enrichment in lactate in human brain tumors during metabolism of [1,2-(13)C]acetate. Neurochem Int 97: 133-136.

Schafer ZT, Grassian AR, Song L, Jiang Z, Gerhart-Hines Z, Irie HY, Gao S, Puigserver P, Brugge JS (2009) Antioxidant and oncogene rescue of metabolic defects caused by loss of matrix attachment. Nature 461: 109-113.

Schoors S, Bruning U, Missiaen R, Queiroz KC, Borgers G, Elia I, Zecchin A, Cantelmo AR, Christen S, Goveia J, Heggermont W, Godde L, Vinckier S, Van Veldhoven PP, Eelen G, Schoonjans L, Gerhardt H, Dewerchin M, Baes M, De Bock K, Ghesquiere B, Lunt SY, Fendt SM, Carmeliet P (2015) Fatty acid carbon is essential for dNTP synthesis in endothelial cells. Nature 520: 192-197.

Schoors S, De Bock K, Cantelmo AR, Georgiadou M, Ghesquiere B, Cauwenberghs S, Kuchnio A, Wong BW, Quaegebeur A, Goveia J, Bifari F, Wang X, Blanco R, Tembuyser B, Cornelissen I, Bouche A, Vinckier S, Diaz-Moralli S, Gerhardt H, Telang S, Cascante M, Chesney J, Dewerchin M, Carmeliet P (2014) Partial and transient reduction of glycolysis by PFKFB3 blockade reduces pathological angiogenesis. Cell Metab 19: 37-48.

Schug ZT, Peck B, Jones DT, Zhang Q, Grosskurth S, Alam IS, Goodwin LM, Smethurst E, Mason S, Blyth K, McGarry L, James D, Shanks E, Kalna G, Saunders RE, Jiang M, Howell M, Lassailly F, Thin MZ, Spencer-Dene B, Stamp G, van den Broek NJ, Mackay G, Bulusu V, Kamphorst JJ, Tardito S, Strachan D, Harris AL, Aboagye EO, Critchlow SE, Wakelam MJ, Schulze A, Gottlieb E (2015) Acetyl-CoA synthetase 2 promotes acetate utilization and maintains cancer cell growth under metabolic stress. Cancer Cell 27: 57-71.

Sellers K, Fox MP, Bousamra 2nd M, Slone SP, Higashi RM, Miller DM, Wang Y, Yan J, Yuneva MO, Deshpande R, Lane AN, Fan TW (2015) Pyruvate carboxylase is critical for non-small-cell lung cancer proliferation. J Clin Invest 125: 687-698.

Shlomi T, Benyamini T, Gottlieb E, Sharan R, Ruppin E (2011) Genome-scale metabolic modeling elucidates the role of proliferative adaptation in causing the Warburg effect. PLoS Comput Biol 7: e1002018.

Sousa CM, Biancur DE, Wang X, Halbrook CJ, Sherman MH, Zhang L, Kremer D, Hwang RF, Witkiewicz AK, Ying H, Asara JM, Evans RM, Cantley LC, Lyssiotis CA, Kimmelman AC (2016) Pancreatic stellate cells support tumour metabolism through autophagic alanine secretion. Nature 536: $479-483$
Tardito S, Oudin A, Ahmed SU, Fack F, Keunen O, Zheng L, Miletic H, Sakariassen PO, Weinstock A, Wagner A, Lindsay SL, Hock AK, Barnett SC, Ruppin E, Morkve SH, Lund-Johansen M, Chalmers AJ, Bjerkvig R, Niclou SP, Gottlieb E (2015) Glutamine synthetase activity fuels nucleotide biosynthesis and supports growth of glutamine-restricted glioblastoma. Nat Cell Biol 17: 1556-1568.

Tonjes M, Barbus S, Park YJ, Wang W, Schlotter M, Lindroth AM, Pleier SV, Bai AH, Karra D, Piro RM, Felsberg J, Addington A, Lemke D, Weibrecht I, Hovestadt V, Rolli CG, Campos B, Turcan S, Sturm D, Witt H, Chan TA, Herold-Mende C, Kemkemer R, Konig R, Schmidt K, Hull WE, Pfister SM, Jugold M, Hutson SM, Plass C, Okun JG, Reifenberger G, Lichter P, Radlwimmer B (2013) BCAT1 promotes cell proliferation through amino acid catabolism in gliomas carrying wild-type IDH1. Nat Med 19: 901-908.

Tummala KS, Gomes AL, Yilmaz M, Grana O, Bakiri L, Ruppen I, Ximenez-Embun P, Sheshappanavar V, Rodriguez-Justo M, Pisano DG, Wagner EF, Djouder N (2014) Inhibition of de novo NAD $(+)$ synthesis by oncogenic URI causes liver tumorigenesis through DNA damage. Cancer Cell 26: 826-839.

Vander Heiden MG, Cantley LC, Thompson CB (2009) Understanding the Warburg effect: the metabolic requirements of cell proliferation. Science 324: $1029-1033$.

Veldhoen M, Hirota K, Christensen J, O'Garra A, Stockinger B (2009) Natural agonists for aryl hydrocarbon receptor in culture medium are essential for optimal differentiation of Th17 T cells. J Exp Med 206: 43-49.

Veldhoen M, Hirota K, Westendorf AM, Buer J, Dumoutier L, Renauld JC, Stockinger B (2008) The aryl hydrocarbon receptor links TH17-cellmediated autoimmunity to environmental toxins. Nature 453: 106-109.

Yao CH, Fowle-Grider R, Mahieu NG, Liu GY, Chen YJ, Wang R, Singh M, Potter GS, Gross RW, Schaefer J, Johnson SL, Patti GJ (2016) Exogenous fatty acids are the preferred source of membrane lipids in proliferating fibroblasts. Cell Chem Biol 23: 483-493.

Yi W, Clark PM, Mason DE, Keenan MC, Hill C, Goddard 3rd WA, Peters EC, Driggers EM, Hsieh-Wilson LC (2012) Phosphofructokinase 1 glycosylation regulates cell growth and metabolism. Science 337: 975-980.

Yuneva MO, Fan TW, Allen TD, Higashi RM, Ferraris DV, Tsukamoto T, Mates JM, Alonso FJ, Wang C, Seo Y, Chen X, Bishop JM (2012) The metabolic profile of tumors depends on both the responsible genetic lesion and tissue type. Cell Metab 15: 157-170.

Zhao H, Yang L, Baddour J, Achreja A, Bernard V, Moss T, Marini JC, Tudawe T, Seviour EG, San Lucas FA, Alvarez H, Gupta S, Maiti SN, Cooper L, Peehl D, Ram PT, Maitra A, Nagrath D (2016) Tumor microenvironment derived exosomes pleiotropically modulate cancer cell metabolism. Elife 5: e10250.

Zong WX, Rabinowitz JD, White E (2016) Mitochondria and cancer. Mol Cell 61: 667-676.

(c) (1)(2) This work is licensed under the Creative Commons (c) ${ }_{\mathrm{BY}} \mathrm{Nc}$ sA Attribution-Non-Commercial-Share Alike 4.0 International License. To view a copy of this license, visit http:// creativecommons.org/licenses/by-nc-sa/4.0/

(C) The Author(s) named above 2017 